\title{
Extending Technology Acceptance Model for Proximity Mobile Payment via Organisational Semiotics
}

\author{
Yu-Chun Pan ${ }^{1}$, Aimee Jacobs ${ }^{2}$, Chekfoung Tan ${ }^{3}$, and Sanaa Askool ${ }^{4}$ \\ ${ }^{1 ; 3}$ University of West London, School of Computing and Engineering, London, UK \\ y.pan@uwl.ac.uk; chekfoung.tan@uwl.ac.uk \\ ${ }^{2}$ Craig School of Business, California State University, Fresno, California, USA \\ ajacobs@csufresno. edu \\ ${ }^{4}$ Dar Al-Hekma University, Hekma School of Business, Jeddah, Saudi Arabia \\ saskool@dah.edu.sa
}

\begin{abstract}
.
The growth of mobile technologies and smartphones is reshaping the individual and organisational behaviour which affect the business environment. One of the key challenges of mobile payment is how to understand and manage user expectations and technology acceptance. Therefore, to better understand mobile payment use and acceptance, we need to analyse the factors and barriers that influence technology use. The investigation uses Technology Acceptance Model in conjunction with Organisational Semiotics, a socio-technical method of design, to overcome possible limitations addressed in research. This approach offers methods that can help to develop a research model for mobile payment use focusing on technical and social aspects.
\end{abstract}

Keywords: Mobile Payment, Proximity Mobile Payment, Technology Acceptance Model, Organisational Semiotics, Semiotics, Adoption

\section{Introduction}

With the widespread of mobile devices and users' appetite for convenient and timely payment, the use of proximity mobile payment (m-payment) is expected to continue to grow. According to Statista [1], the global revenue for proximity m-payment market is expected to reach 930 billion US dollars in 2018. However, according to WorldPay [2], whilst $30 \%$ of customers have used mobile devices for contactless (tap and go) payment, $75 \%$ of customers prefer to use their credit or debit cards for contactless payment in the UK. Despite the growing use, the adoption of m-payment amongst smartphone users is still relatively low [3]. Therefore, it is essential to further investigate the factors of adoption to identify the blocks as well as provide guidance to merchants on how to better encourage users to adopt m-payment.

The main contribution of this paper is the development of an extended Technology Acceptance Model (TAM) for m-payment focusing on both social and technical as- 
pects. This paper meets this aim by analysing the current research in technology acceptance and m-payment and proposing Organisational Semiotics (OS) as a suitable perspective to extend TAM.

\section{Context and Motivation}

Advances in technologies have introduced a wide range of features to mobile devices, which have changed user behaviours significantly. Since the early 1990s, m-payment systems have allowed people to use radio connection between their mobile devices and their mobile network providers to authorise financial transactions. M-payment is considered as a payment or economic exchange for good and/or services via mobile devices through a wireless network or communication technologies [4]. However, such m-payment systems require mobile network coverage and might not always be available. Near Field Communication (NFC) allows a contactless short-range communication facilitating data transmission between mobile devices and payment terminals. With the support of NFC, proximity m-payment allows users with compatible mobile devices to use mpayment function via their mobile phones and portable devices for financial transactions when their devices and Point of Sale (POS) terminals are within a distance of 10 $\mathrm{cm}$. Proximity m-payment eliminates the need for customers to carry and use cash [5] and offers convenience and speed [6].

Since the advent of m-payment, plenty of research has identified the factors of $\mathrm{m}$ payment adoption, including perceived ease of use (PEOU) [7-9], perceived usefulness (PU) [7, 9], trust [8, 10], security and risks [11], costs [12, 13], privacy [14], use context [15], culture [16], and social influence $[12,16]$. TAM and its extensions have been widely applied in m-payment adoption research, as they provide a framework to understand the variables influencing intention to use. However, despite the high adoption of smartphones, the adoption of m-payment is still relatively low [3]. Previous research suggests that adoption is heavily influenced by technology itself as well as user perception of technology. Therefore, there is a need to further develop a framework that comprehensively investigates the adoption factors from a different perspective. OS provides a framework that bridges the gap between technology and people [17], and it can be used to enhance the understanding of adoption factors. The following section introduces TAM and its extensions, as well as OS.

\section{Theoretical Background}

The aim of this section is to explore the various theoretical models proposed for technology use and adoption. Adoption models have roots in information systems (IS), psychology [18], and sociology [19, 20]. However, many researchers ignore the social cultural aspects. Davis [19] stated that group, cultural, or social aspects of decision making, and usage are not considered very much in technology acceptance research. This research intends to bridge this gap by investigating adoption through an OS lens. OS focuses on semiotic aspects to understand and analyse organisations as IS according to the use of signs, text and communication. The following sections provide background 
and context for this research through technology adoption, TAM model and extensions of TAM, and OS, respectively.

\subsection{Technology Acceptance Model (TAM) and its Extensions}

TAM is used as a predictive and explanatory tool for testing user acceptance of technologies with the aim of understanding the impact of external factors on internal beliefs, attitudes, and intentions. The basis of TAM comes from Theory of Reasonable Action (TRA), which suggests the actual behaviour is an outcome of their behavioural intentions to perform the behaviour. These behavioural intentions are constructed jointly by the user's attitude toward the behaviour and subjective norms [18]. TAM was extended to include the determents of Perceived Usefulness (PU) and Perceived Ease-Of Use (PEOU) as shown in Fig. 1.

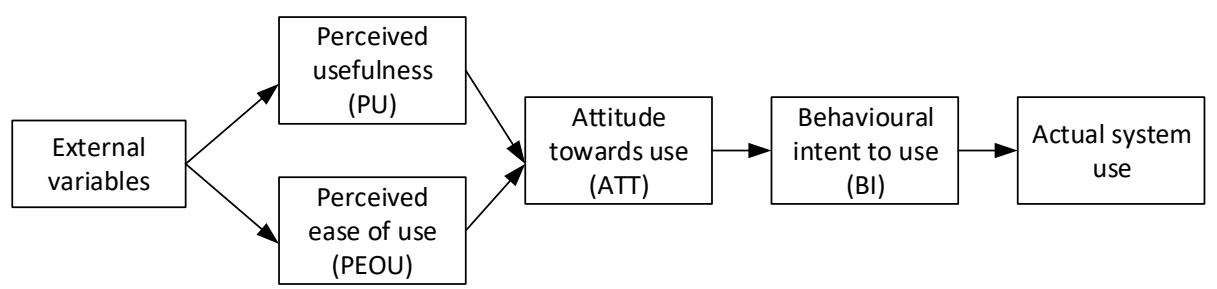

Fig. 1. Original Technology Acceptance Model (TAM)

TAM theorises that the influence of external variables will determine PU and PEOU. PU is defined by Davis [19] as the probability the user's job performance will increase given use of a specific application. PEOU pertains to how effortless the new system will be for the user. These two determinants, PU and PEOU, influence a user's attitude toward using. Both TAM and TRA propose that usage is determined by behavioural intentions, however, TAM differs in that it views intentions as being jointly determined by the person's attitude toward using the system and perceived usefulness [19]. In a recent review [21] of adoption models, researchers found that most studies using TAM either used the original TAM constructs or extended TAM by adding new predictive constructs. Perceived risks are a construct that has been proven [22] to show relevance in adoption of new technologies.

\section{Perceived Risks (PR).}

Perceived risks include two dimensions: the level of uncertainty (the likelihood of certain events happening) and the seriousness of impacts shall the events occur [23]. Before adopting new technologies, people assess the two dimensions of potential risks to determine whether they are willing to take the risks as part of their decision-making process [24]. Such potential risks could include technology and information security, privacy, financial loss and so on $[25,26]$. Technology and information security has a strong influence on user intention to adopt technologies facilitating monetary transactions [26]. Other researchers have identified several dimensions of the perceived risk 
in online shopping field. Zheng et al. [27] propose five dimensions: financial risk, performance risk, social risk, psychological risk, and physical risk, whereas Dai et al. [28] identify three dimensions product, financial and privacy risks.

\section{Limitations of TAM.}

Bagozzi [25] suggests that one model cannot fully explain decisions and behaviours across various technologies and adoption situations causing researchers to overlook essential determinants of decisions and action in favour of using the simplistic TAM model. TAM is further criticised for its focus on the individual user ignoring the social process of IS development and implementation and social consequences [29]. Additionally, TAM focuses on technology use, which takes away from the purpose and benefits that are trying to be achieved. Therefore, decision makers focus on the adoption of technology rather than focusing on behaviour or the combination.

TAM and other associated models of technology acceptance have been questioned [29, 31-33]. Since they do not explain why such groups of the population are more likely to adopt a technology and other groups in a population are less so, regardless of sharing similar individual characteristics; therefore, TAM could not validate across all cultures. For example, TAM was found to be valid for both the United States and Switzerland, but not for Japan due to cultural differences [34]. The impact of uncertainty avoidance was reported as the reason for the difference among participants; Japanese were classified to be high on uncertainty avoidance, and accordingly, they were less eager to adopt a new technology [34]. This research proposes the use of OS to addresses these limitations of the TAM model. OS permits a norm analysis of an organisation's socio-technical components thus identifying the salient factors for adoption of m-payment. The following section introduces OS and its methods.

\subsection{Organisational Semiotics (OS)}

OS applies concepts and methods of semiotics in studying an organisation [35]. Semiotics is the study of signs [36]. A sign can either be an object, an index or a symbol. An object is a sign that conveys message, an index signifies meaning derived by repeated observation, and a symbol refers to a sign associating with norms or rules [37]. An organisation is hence understood as an IS where signs are considered as information.

Scholars [38] have applied OS in extending the behavioural factors in TAM. Semiotics ladder is an OS framework that studies social and technical aspects of an IS [39]. In this research, the IS refers to the m-payment system. The technical aspect consists of three layers: physical layer identifies the physical carrier of storing and processing information such as the mobile devices and servers that host the mobile payment application, empirical layer refers to the way signs are transmitted such as the network technology and communication protocol, and syntactic layer relates to the sign structure and in this case, it is the design of the mobile payment application. The social aspect consists of three layers: semantic layer, describes the meaning of signs which in this case how information of the mobile payment system being perceived by the users, pragmatic layer studies how users perceive signs such as studying users' intention in using 
the mobile payment system, and social layer examines the interpretation of signs where new knowledge is created, for example, if users acknowledge the benefits of using the mobile payment system outweigh the costs (including sacrifice of privacy), this would prompt them in using the system. In OS, a norm "is more like a field of force that makes the members of a community tend to behave or think in a certain way" [39]. The users' behaviour can then be studied through norms [38]. In an organisation, norms are seen as all types of signs [17]. A sign can be an object, or an effect produced by an object that conveys information. Norms impact on how a user behaves that leads to perform certain actions, which will generate more signs that leads to subsequent actions. Stamper [39] proposes the Organisational Containment Analysis (OCA) to analyse norms of an organisation. OCA consists of three layers: informal, formal and technical. The informal layer refers to organisational culture, customs and values that are reflected as beliefs, habits and patterns of members within the organisation. These norms are part of the culture in the organisation, so they are usually being applied informally. The formal layer denotes the rules and bureaucracy to perform the organisational activities. The technical layer automates the norms captured in the informal and formal layer.

\section{OS Perspective to TAM for Mobile Payment}

According to Bagozzi [29], the social aspect is a gap in TAM research because while sometimes we seem to be acting in isolation, spontaneously, deliberatively, or in response to social pressure, we typically act interpersonally, or as agents of organisations, or collectively. Therefore, we adopt OS to analyse the acceptance of m-payment. The OS analysis of m-payment can be categorised into six distinctive layers (Fig. 2).

\begin{tabular}{|l|l|l|}
\hline OCA & OSF & \multicolumn{2}{|c|}{$\begin{array}{l}\text { Social World: Social influence, peer } \\
\text { pressure, perceived risks, confidence } \\
\text { in service providers, culture... }\end{array}$} \\
\hline Informal & Human Information Functions $\begin{array}{l}\text { Pragmatics: Time saving, convenience, ac- } \\
\text { Formal }\end{array}$ & \multicolumn{3}{|c|}{$\begin{array}{l}\text { Semantics: Contactless financial transactions, } \\
\text { regulations for financial transactions, service } \\
\text { agreements, terms and conditions ... }\end{array}$} \\
\hline \multirow{5}{*}{ Technical } & The Platform & $\begin{array}{l}\text { Syntactics: Design and structure of M-payment appli- } \\
\text { cation, compatibility, security protocol, encryption, ver- } \\
\text { ification, user guide... }\end{array}$ \\
\cline { 2 - 4 } & \multicolumn{2}{|c|}{$\begin{array}{l}\text { Empirics: NFC, transaction platform, portal, internet con- } \\
\text { nectivity, connection speed and liability, archives... }\end{array}$} \\
\cline { 2 - 4 } & Physical World: POS terminal, mobile devices, server, cables, database... \\
\hline
\end{tabular}

Fig. 2. Organisational Semiotics Framework (OSF) with Organisational Containment Analysis (OCA) for M-Payment 
The analysis identifies the requirements for m-payment adoption in the human information functions and the IT platform respectively. This analysis may provide the foundation for m-payment adoption development. The OCA helps to identify socio-technical factors that contribute to adoption of m-payment. Based on previous research in technology adoption and OS, we integrate the OS Ladder and OCA (Fig. 2) to propose a conceptual model for understanding m-payment acceptance (Fig. 3). The model can be explained as follows: m-payment acceptance can be evaluated in three levels, technical (technology characteristics), formal (organizational antecedents), and informal (external environment). These three levels affect the intention to use and adopt m-payment. The advantages obtained by using $\mathrm{m}$-payment will either positively or negatively influence user acceptance.

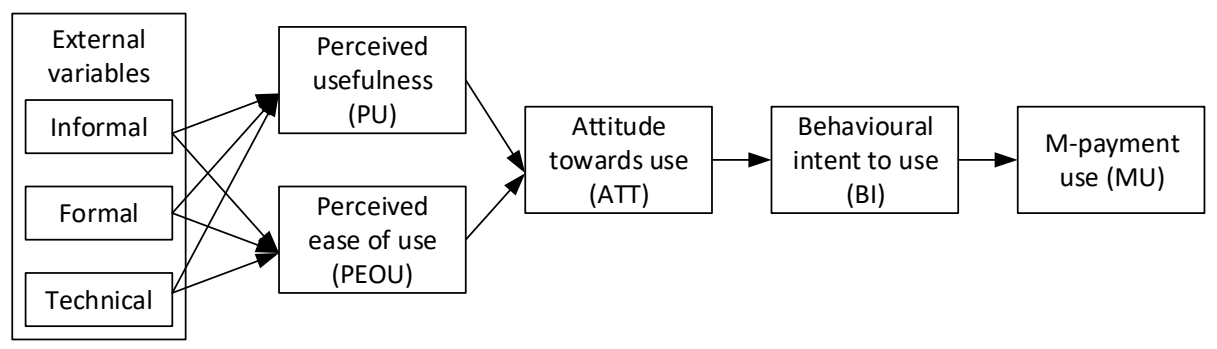

Fig. 3. Conceptual Model for Understanding M-Payment Acceptance

Factors that contribute to the adoption of m-payment include speed and convenience through contactless payments [6], which can be considered as PEOU, PU and intent to use in the informal layer. The level of perceived risks of a technology could affect the level of technology use and acceptance; where risk is perceived to be high, adopters would be less willing to adopt the technology [40]. Lwin et al. [41] concluded that consumers' concerns about security risk are one of the key factors for electronic services adoption. In the context of m-payment, users might be concerned with risks related to privacy, personal data and, transactions [25]. Therefore, whether users feel comfortable using m-payment due to security, privacy and risk concerns form key informal norms. Additionally, difficulties that users may face due to security measurements/verification and the fears that companies have not taken adequate steps to reduce transaction risks could also negatively affect transaction intentions.

The findings also identify the formal factors of costs, context of use, customers' perceived risks of privacy, personal data \& transactions which should be lessened by an organisation's regulations and policies to reduce these risks. Although perceived risks and security are informal norms, the formal policies and regulations can influence users' perception of risks and security. Therefore, the service agreements provided by m-payment service providers, e.g. Google and Apple, play a key role. Technology and information security has a strong influence on user intention to adopt technologies facilitating monetary transactions [26]. Hence, the relevant regulations set by authorities to prevent users' financial loss form the formal norms for m-payment. Other formal factors also include costs, security and privacy policies, risk management policies, availability of assistance for online and mobile service. 
Mobile transactions are conducted with the following technical factors; mobile devices, along with mobile technology, radio connections and wireless telecommunications. NFC and payment terminals such as POS terminals and m-payment applications are all necessary for m-payment use. Also, technologies to help ensure privacy and security should be carefully thought out. For customers to adopt m-payment all these socio-technical factors should be considered by organisations that want to implement an m-payment service. Moreover, Suh and Han [42] indicate that consumers who want to buy products or services online have concerns about security due to the vulnerabilities of website forms. Accordingly, several factors such as protection, encryption, verification, and authentication should be the antecedent of perceived security [43].

\section{$5 \quad$ Discussion \& Conclusion}

M-payment system has empowered the digital transformation of business and has been adopted by several industries. Although this new paying method shows several advantages when compared with traditional ways, consumers have been slow to adopt. TAM has been used as a suitable user acceptance model to understand technology adoption, however, several gaps were reported such as a gap in linking technical and social factors. Therefore, the purpose of this paper is to address a TAM gap with OS as it provides a structural approach in studying organisational norms through individual behaviour. OS as a theoretical lens to examine the factors that affect adoption in technical and social levels was used to extend TAM.

The OS Ladder and OCA were used to analyse the factors that influence the adoption of mobile payment. This analysis indicates that the socio-technical factors can be considered either as enablers or inhibiters. It was found that m-payment adoption can produce the benefits of enhanced speed and convenience through contactless payments. Inhibitors may include level of perceived risks, namely risks related to security, privacy, personal data and, transactions. Other formal factors also include costs, security and privacy policies, risk management policies, availability of personal assistance for online and mobile service. Additionally, several factors such as protection, encryption, verification, and authentication should be the antecedent of perceived security in the technical layer. These factors were then used to extend TAM. The proposed conceptual model (Fig. 3) with supporting OS ladder and OCA (Fig. 2) serves as a backbone methodology for organisations who would like to implement m-payment for their customers. The research model provides a useful framework for organisations wanting to develop the infrastructure for m-payment transactions. This research enables organisations to consider the social perspective of the adoption factor in m-payment that should be taken into consideration when planning to implement such a system.

A limitation, however, is that the research framework is based on literature review without empirical studies. However, the proposed model presents the relationships between the technical and social challenges of m-payment. Future investigation will look into alternatives to OS as an extension to TAM for m-payment adoption, for example, Everitt Rogers's Technology Adoption Lifecycle. Further research can be applied to 
test the internal and external validity of the theoretical propositions by collecting empirical data from consumers.

In conclusion, this paper focused on the extension of TAM based on OS. The analysis highlights the requirements through the six layers in OS framework focusing on semantic, pragmatic and social aspects of m-payment without disregarding the social characteristics.

\section{References}

1. Statista: Total revenue of global mobile payment market from 2015 to 2019 (in billion U.S. dollars), https://www.statista.com/statistics/226530/mobile-payment-transaction-volumeforecast/

2. WorldPay: WorldPay Consumer Behaviour and Payments Report 2017: What's driving today's consumers? (2017)

3. Deloitte: Contactless mobile payments (finally) gain momentum. (2015)

4. Liu, J., J.Kauffman, R., Ma, D.: Competition, cooperation, and regulation: Understanding the evolution of the mobile payments technology ecosystem. Electron. Commer. Res. Appl. 14, 372-391 (2015). doi:10.1016/J.ELERAP.2015.03.003

5. Pham, T.-T.T., Ho, J.C.: The effects of product-related, personal-related factors and attractiveness of alternatives on consumer adoption of NFC-based mobile payments. Technol. Soc. 43, 159-172 (2015). doi:10.1016/J.TECHSOC.2015.05.004

6. Teo, A.-C., Tan, G.W.-H., Ooi, K.-B., Hew, T.-S., Yew, K.-T.: The effects of convenience and speed in m-payment. Ind. Manag. Data Syst. 115, 311-331 (2015). doi:10.1108/IMDS08-2014-0231

7. Kim, C., Mirusmonov, M., Lee, I.: An empirical examination of factors influencing the intention to use mobile payment. Comput. Human Behav. 26, 310-322 (2010). doi:10.1016/J.CHB.2009.10.013

8. Shin, D.-H.: Modeling the Interaction of Users and Mobile Payment System: Conceptual Framework. Int. J. Hum. Comput. Interact. 26, 917-940 (2010). doi:10.1080/10447318.2010.502098

9. Koenig-Lewis, N., Marquet, M., Palmer, A., Zhao, A.L.: Enjoyment and social influence: predicting mobile payment adoption. Serv. Ind. J. 35, 537-554 (2015). doi:10.1080/02642069.2015.1043278

10. Lu, Y., Yang, S., Chau, P.Y.K., Cao, Y.: Dynamics between the trust transfer process and intention to use mobile payment services: A cross-environment perspective. Inf. Manag. 48, 393-403 (2011). doi:10.1016/J.IM.2011.09.006

11. Arvidsson, N.: Consumer attitudes on mobile payment services - results from a proof of concept test. Int. J. Bank Mark. 32, 150-170 (2014). doi:10.1108/IJBM-05-2013-0048

12. Hongxia, P., Xianhao, X., Weidan, L.: Drivers and barriers in the acceptance of mobile payment in China. In: 2011 International Conference on E-Business and E-Government (ICEE). pp. 1-4. IEEE (2011)

13. Mallat, N.: Exploring consumer adoption of mobile payments - A qualitative study. J. Strateg. Inf. Syst. 16, 413-432 (2007). doi:10.1016/j.jsis.2007.08.001

14. Slade, E.L., Williams, M.D., Dwivedi, Y.K.: Mobile payment adoption: Classification and review of the extant literature. Mark. Rev. 13, 167-190 (2013). doi:10.1362/146934713X13699019904687

15. Mallat, N., Rossi, M., Tuunainen, V.K., Öörni, A.: The impact of use context on mobile services acceptance: The case of mobile ticketing. Inf. Manag. 46, 190-195 (2009). 
doi:10.1016/J.IM.2008.11.008

16. Alalwan, A.A., Rana, N.P., Dwivedi, Y.K., Lal, B., Williams, M.D.: Adoption of Mobile Banking in Jordan: Exploring Demographic Differences on Customers' Perceptions. Presented at the October 13 (2015)

17. Stamper, R.K.: Information Systems as a Social Science. In: Information System Concepts: An Integrated Discipline Emerging. pp. 1-51. Springer US, Boston, MA (2000)

18. Fishbein, M., Ajzen, I.: Belief, attitude, intention, and behavior : an introduction to theory and research. Addison-Wesley Pub. Co (1975)

19. Davis, F.D.: Perceived Usefulness, Perceived Ease of Use, and User Acceptance of Information Technology. MIS Q. 13, 319 (1989). doi:10.2307/249008

20. Venkatesh, V., Davis, F.D.: A Theoretical Extension of the Technology Acceptance Model: Four Longitudinal Field Studies. Manage. Sci. 46, 186-204 (2000). doi:10.1287/mnsc.46.2.186.11926

21. Chhonker, M.S., Verma, D., Kar, A.K.: Review of Technology Adoption frameworks in Mobile Commerce. Procedia Comput. Sci. 122, 888-895 (2017). doi:10.1016/j.procs.2017.11.451

22. Zimmer, J.C., Arsal, R.E., Al-Marzouq, M., Grover, V.: Investigating online information disclosure: Effects of information relevance, trust and risk. Inf. Manag. 47, 115-123 (2010). doi:10.1016/J.IM.2009.12.003

23. Bauer, R.: Consumer Behavior as Risk Taking. In: Risk Taking and Information Handling in Consumer Behavior. Harvard University Press, Cambridge, MA. (1967)

24. Featherman, M.S., Pavlou, P.A.: Predicting e-services adoption: a perceived risk facets perspective. Int. J. Hum. Comput. Stud. 59, 451-474 (2003). doi:10.1016/S10715819(03)00111-3

25. Bauer, H.H., Reichardt, T., Barnes, S.J., Neumann, M.M.: Driving Consumer Acceptance of Mobile Marketing: A Theoretical Framework and Empirical Study. J. Electron. Commer. Res. 6, (2005)

26. Cheng, T.C.E., Lam, D.Y.C., Yeung, A.C.L.: Adoption of internet banking: An empirical study in Hong Kong. Decis. Support Syst. 42, 1558-1572 (2006). doi:10.1016/J.DSS.2006.01.002

27. Zheng, L., Favier, M., Huang, P.: CHINESE CONSUMER PERCEIVED RISK AND RISK RELIEVERS IN E-SHOPPING FOR CLOTHING. J. Electron. Commer. Res. 13, (2012)

28. Dai, B., Forsythe, S., Kwon, W.-S.: THE IMPACT OF ONLINE SHOPPING EXPERIENCE ON RISK PERCEPTIONS AND ONLINE PURCHASE INTENTIONS: DOES PRODUCT CATEGORY MATTER? J. Electron. Commer. Res. 15, (2014)

29. Richard P. Bagozzi: The Legacy of the Technology Acceptance Model and a Proposal for a Paradigm Shift. J. Assoc. Inf. Syst. 8, (2007)

30. Venkatesh, V., Bala, H.: Technology Acceptance Model 3 and a Research Agenda on Interventions. Decis. Sci. 39, 273-315 (2008). doi:10.1111/j.1540-5915.2008.00192.x

31. Izak Benbasat, Barki, H.: Quo vadis TAM? J. Assoc. Inf. Syst. 8, (2007)

32. Yousafzai, S.Y., Foxall, G.R., Pallister, J.G.: Technology acceptance: a meta-analysis of the TAM: Part 1. J. Model. Manag. 2, 251-280 (2007). doi:10.1108/17465660710834453

33. Viswanath Venkatesh, Davis, F.D., Morris, M.G.: Dead Or Alive? The Development, Trajectory And Future Of Technology Adoption Research. J. Assoc. Inf. Syst. 8, 267-286 (2007)

34. Straub, D., Keil, M., Brenner, W.: Testing the technology acceptance model across cultures: A three country study. Inf. Manag. 33, 1-11 (1997). doi:10.1016/S0378-7206(97)00026-8

35. Liu, K.: Semiotics in Information System Engineering. Cambridge University Press, Cambridge, UK (2000) 
36. Peirce, C.S.: Collected Papers of Charles Sanders Peirce: Pragmaticisms and Pragnoaticism, Scientific Metaphysics. Belknap Press, MA, US (1935)

37. Stamper, R.K.: Towards a Theory of Information: Information: Mystical Fluid or a Subject for Scientific Enquiry? Comput. J. 28, 195-199 (1985). doi:10.1093/comjn1/28.3.195

38. Al-Rajhi, M., Liu, K., Nakata, K.: A Conceptual Model for Acceptance of Information Systems: An Organizational Semiotic Perspective. In: Americas Conference on Information Systems (AMCIS). p. 348 (2010)

39. Stamper, R.K.: Organisational Semiotics: Informatics without the computer? In: L. Kecheng P. Bogh_Anderson and R. K. Stamper, R.J.C. (ed.) Information, Organisation and Technology: studies in organisational semiotics. Kluwer, Dordecht, Netherlands (2001)

40. Shoemaker, R.W., Shoaf, F.R.: Behavioral Changes in the Trial of New Products, http://www.jstor.org/stable/2488751

41. Lwin, M., Wirtz, J., Williams, J.D.: Consumer online privacy concerns and responses: a power-responsibility equilibrium perspective. J. Acad. Mark. Sci. 35, 572-585 (2007). doi:10.1007/s11747-006-0003-3

42. Suh, B., Han, I.: The Impact of Customer Trust and Perception of Security Control on the Acceptance of Electronic Commerce. Int. J. Electron. Commer. 7, 135-161 (2003)

43. Chellappa, R.K., Pavlou, P.A.: Perceived information security, financial liability and consumer trust in electronic commerce transactions. Logist. Inf. Manag. 15, 358-368 (2002). doi:10.1108/09576050210447046 